\title{
Dravet Syndrome: A Case Series
}

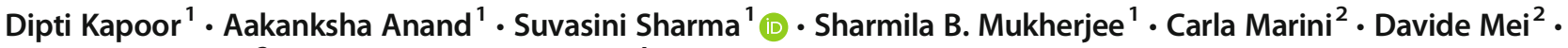 Saurabh S Chopra ${ }^{3} \cdot$ Akbar Mohaned Chettali $^{4}$}

Received: 14 January 2020 / Accepted: 3 June 2020 / Published online: 26 June 2020

(C) Dr. K C Chaudhuri Foundation 2020

To the Editor: Dravet syndrome (DS) is a rare but severe earlylife epilepsy [1]. The timely diagnosis of this condition requires a high degree of clinical suspicion, because the MRI is typically normal and the EEG findings are nonspecific [2]. However, the clinical presentation is unique, with the onset of recurrent, convulsive seizures, which are often prolonged and triggered by fever, in a developmentally normal infant [3]. Pathogenic variants in the SCN1A gene, which code for the $1 \alpha$ subunit of the neuronal, voltage-gated sodium channel, are found in as many as $85 \%$ of affected children [4]. The children eventually develop intractable seizures and neurodevelopmental impairment.

We report the electroclinical data of 9 genetically confirmed DS children from our centre.

All nine children had presented to us with history and clinical progression compatible with DS. The mean age at onset of seizures was $5 \mathrm{mo}$. The triggering factor in all patients was fever associated with routine immunisation or infections. EEG and MRI brain of all the patients were normal at the onset. In follow up, 3 developed multifocal epileptiform discharges, and 1 developed variant hypsarrhythmia. Family history of febrile seizures was present in 4 patients. Two children had initially been started on phenytoin and carbamazepine outside, with resultant clinical deterioration in the form of increased seizure frequency.

Suvasini Sharma

sharma.suvasini@gmail.com

1 Neurology Division, Department of Pediatrics, Lady Hardinge Medical College and Associated Kalawati Saran Children's Hospital, New Delhi, India

2 Pediatric Neurology Unit, Children's Hospital A. Meyer, Florence, Italy

3 Department of Pediatrics, Max Superspeciality Hospital, Saket, New Delhi, India

4 Department of Pediatrics, The Royal Hospital, Ministry of Health, Muscat, Oman
The seizure control was suboptimal in all, with seizures occurring at a frequency of 1-2 per month in 8 and daily seizures in 1 child, despite the use of multiple anticonvulsant drugs. All of the patients had associated co-morbidities, including global developmental delay (all), autistic features (4/9), hyperactivity (3/9) and ataxia (3/9). Genetic testing revealed pathogenic variants in SCNIA gene in 8 children (exon deletions in 4 , missense mutations in 2 patients and truncating mutation in one patient) and $S C N 1 B$ gene mutation in 1 child.

The clinical phenotype of our patients resembles that reported worldwide $[1,4]$. Early onset prolonged fever triggered seizures, subsequent development of intractable epilepsy and neurodevelopmental impairments such as developmental delay, autistic features, hyperactivity and ataxia form the phenotype. Early recognition is important to avoid inappropriate treatment with sodium channel blockers and for genetic confirmation.

\section{Compliance with Ethical Standards}

Conflict of Interest None.

\section{References}

1. Wu YW, Sullivan J, McDaniel SS, et al. Incidence of Dravet syndrome in a US population. Pediatrics. 2015;136:1310-5.

2. Bayat A, Hjalgrim H, Moller RS. The incidence of SCN1A-related Dravet syndrome in Denmark is 1:22,000: a population-based study from 2004 to 2009. Epilepsia. 2015;56:36-9.

3. Brunklaus A, Ellis R, Reavey E, Forbes GH, Zuberi SM. Prognostic, clinical and demographic features in SCN1A mutation-positive Dravet syndrome. Brain. 2012;135:2329-36.

4. Ragona F, Brazzo D, De Giorgi I, et al. Dravet syndrome: early clinical manifestations and cognitive outcome in 37 Italian patients. Brain Dev. 2010;32:71-7.

Publisher's Note Springer Nature remains neutral with regard to jurisdictional claims in published maps and institutional affiliations. 